\title{
A prospective study of coffee intake and pancreatic cancer: results from the NIH-AARP Diet and Health Study
}

\author{
K A Guertin *, , N D Freedman ${ }^{1}$, E Loftfield ${ }^{1}$, R Z Stolzenberg-Solomon ${ }^{1}$, B I Graubard ${ }^{2}$ and R Sinha ${ }^{1}$ \\ ${ }^{1}$ Nutritional Epidemiology Branch, Division of Cancer Epidemiology and Genetics, National Cancer Institute, National Institutes of \\ Health (NIH), Department of Health and Human Services, 9609 Medical Center Drive, Room 6E326, MSC 9760, Bethesda, MD \\ 20892, USA and 2Biostatistics Branch, Division of Cancer Epidemiology and Genetics, National Cancer Institute, National Institutes \\ of Health (NIH), Department of Health and Human Services, Bethesda, MD, USA
}

Background: Evidence evaluating the association between type of coffee intake (caffeinated, decaffeinated) and risk of pancreatic cancer is limited.

Methods: In the US NIH-AARP Diet and Health Study, we used Cox proportional hazards regression to estimate hazard ratios and 95\% confidence intervals (Cls) for coffee intake and risk of pancreatic cancer among 457366 US adults.

Results: Over 4155256 person-years of follow-up, 1541 incident first primary pancreatic cancers occurred. Following detailed adjustment for tobacco smoking history, risk estimates for coffee drinking were not statistically significant; compared with never drinkers of coffee, the hazard ratios (95\% Cl) were 1.05 (0.85-1.30), 1.06 (0.86-1.31), $1.03(0.85-1.25), 1.00$ (0.79-1.25), and 1.24 (0.931.65) for $<1,1,2-3,4-5$, and $\geq 6$ cups per day, respectively ( $P$-value for trend 0.46$)$. The observed null association was consistent across all examined strata (sex, smoking status, coffee caffeination, and prevalent diabetes).

Conclusions: In a prospective study of coffee intake with the largest number of pancreatic cancer cases to date, we did not observe an association between total, caffeinated, or decaffeinated coffee intake and pancreatic cancer.

Pancreatic cancer is highly lethal, with a 5-year survival rate of $7 \%$ (Howlader, 2015). As there is currently no screening test for this disease, identification of modifiable factors that may lower disease risk is important. Coffee, a common dietary exposure in the United States and worldwide, contains bioactive compounds that may alter cancer risk (Cornelis, 2015; Guertin and Loftfield et al, 2015); however, evidence evaluating the association between type of coffee intake (caffeinated, decaffeinated) and risk of pancreatic cancer is limited.

In 2012, the American Institute of Cancer Research concluded that a substantial effect of coffee on risk of pancreatic cancer was unlikely (World Cancer Research Fund and American Institute for Cancer Research, 2012). However, results from prior meta-analyses are conflicting (Nishi et al, 1996; Dong et al, 2011; Turati et al, 2012). Additionally, a recent pooled analysis of prospective studies concluded that there was no association between coffee intake and risk of pancreatic cancer (Genkinger et al, 2012), but interpretation of these results is difficult due to the appreciable heterogeneity between the 14 included international studies.

Although smoking status and caffeine are important considerations in the association between coffee intake and pancreatic cancer, most previous studies had insufficient case numbers to examine associations stratified by smoking status and lacked information on caffeine type. Smoking is a risk factor for pancreatic cancer (Maisonneuve and Lowenfels, 2014) and is highly correlated with coffee drinking (Nomura et al, 1986; Nilsson et al, 2010; Ren et al, 2010). The European Prospective Study into Nutrition and Cancer (EPIC) recently reported no overall association for high coffee drinking (fourth quartile vs 
non-drinking) and pancreatic cancer, but did observe increased risk among moderately low drinkers (those in the second quartile) of caffeinated coffee (Bhoo-Pathy et al, 2013).

We sought to clarify the association between coffee drinking and pancreatic cancer risk in a large US cohort. With 1541 incident pancreatic cancers, the NIH-AARP Diet and Health Study (http://dietandhealth.cancer.gov/) includes more than two times the number of cases as compared with the largest single prospective study to date (Bhoo-Pathy et al, 2013), and allows for further investigation of potential differences in risk between caffeinated and decaffeinated coffee.

\section{MATERIALS AND METHODS}

Study population. The NIH-AARP Diet and Health Study, detailed elsewhere (http://dietandhealth.cancer.gov/) (Schatzkin et al, 2001), included 566398 participants who responded to the mailed study questionnaire, which collected data on demographics, health-related behaviours, and diet. At baseline, participants were aged 50-71 years and resided in one of six US states or two metropolitan areas. We included 457366 participants with nonmissing data on coffee intake and smoking who had plausible dietary intakes, did not have prevalent cancer at baseline (except non-melanoma skin cancer), were not proxy respondents, and were still alive upon receipt of the study questionnaire. The Special Studies Institutional Review Board at the National Cancer Institute approved this study, and all participants provided informed consent.

Ascertainment of pancreatic cancer cases. Cancer cases were identified by linkage of the NIH-AARP cohort to 11 state cancer registries and the National Death Index; it is estimated that 90\% of cancers in the NIH-AARP cohort are captured by these cancer registries (Michaud et al, 2005). Our analyses were limited to first primary cancers of the exocrine pancreas, defined as codes C25.0C25.3 and C25.7-C25.9 in the International Classification of Diseases for Oncology, third edition (World Health Organization, 2010); we excluded non-exocrine pancreatic cancers (histology types $8150-8155,8240,8246$, and 8502 ) as the etiology of these cancers is thought to differ.

Assessment of coffee intake and covariates. At study baseline, participants reported their typical coffee intake and whether they predominantly (more than half the time) drank caffeinated or decaffeinated coffee on a food frequency questionnaire. Covariates that were also assessed at baseline included age, sex, smoking, alcohol use, education, diabetes, and race.

Statistical analysis. We used Cox proportional hazards regression to estimate hazard ratios and $95 \%$ confidence intervals for pancreatic cancer, using non-drinkers of coffee (reported never drinking coffee during the past year) as the referent group and person-years as the time metric; person-years were calculated beginning on the date the questionnaire was returned until the date of cancer diagnosis or the date of censoring, which included movement out of the registry area, loss to follow-up, death, or the end of follow-up (31 December 2006), whichever came first. In our primary models, we adjusted for age, sex, and comprehensive tobacco smoking status; details on smoking categories and additional covariates in the multivariate-adjusted models are provided in Table 1 .

In secondary analyses, we examined the association between coffee intake and pancreatic cancer across prespecific subgroups, including sex, smoking status, type of coffee predominantly consumed (caffeinated or decaffeinated), and prevalent diabetes. We tested the proportional hazards assumption by testing for an interaction between coffee intake and person-years. To examine possible effects of reverse causation, namely whether preclinical disease might alter coffee intake, we conducted lag analyses that started follow-up 2 years after the baseline time point. We conducted all analyses using SAS 9.3 (SAS Institute, Cary, NC, USA) with two-sided tests of statistical significance; $P$-values $<0.05$ were interpreted as statistically significant.

\section{RESULTS}

The mean age of our cohort at baseline was 62 years, and the sample was largely comprised of non-Hispanic whites. Approximately $90 \%$ of the study sample reported drinking coffee (Supplementary Table 1). Among the 457366 participants in our study, $57 \%$ primarily drank caffeinated coffee and $30 \%$ primarily drank decaffeinated coffee. Compared with non-drinkers and low coffee consumers, high coffee consumers were more likely to be male, non-Hispanic White, married, less well educated, and smokers. They consumed greater amounts of alcohol, dietary fats, and total calories but lower amounts of fruits, vegetables, and foods with folic acid (Supplementary Table 1). Among these 457366 participants, 1541 cancers of the exocrine pancreas occurred over $\sim 4.2$ million person-years of follow-up (Supplementary Table 1). Although models adjusted only for age and sex suggested a statistically significant higher risk of pancreatic cancer with higher coffee intake, the association was substantially attenuated after extensive adjustment for smoking (Table 1). Adjustment for additional covariates did not appreciably alter risk estimates (change $<1 \%$ ). The interaction term between coffee intake and person-years, which tested the proportional hazards assumption, was not statistically significant $(P=0.52)$. Similar results were observed when we used coffee drinkers of $<1$ cup per day as the referent group.

The association did not differ by sex (Table 1), tobacco smoking (Table 2), or self-reported history of diabetes (data not shown). Lastly, the association did not differ appreciably between participants drinking predominantly caffeinated and decaffeinated coffee (Table 3 ), or in analyses that excluded the first 2 years of follow-up (Supplementary Table 2).

\section{DISCUSSION}

In this large US prospective study, there was no association between total, caffeinated, or decaffeinated coffee intake and risk of pancreatic cancer following adjustment for smoking. Similarly, null findings were observed in never, former, and current cigarette smokers, among men and women, and by stratum of self-reported diabetes at baseline.

The significant association we observed in age- and sex-adjusted models, which suggested increased risk of pancreatic cancer at higher coffee intakes, is likely because of residual confounding by smoking. Smoking is an important risk factor for pancreatic cancer (Bosetti et al, 2012; Klein et al, 2013), and as smoking and coffee drinking are highly correlated behaviours in NIH-AARP (Guertin et al, 2015) and other (Nomura et al, 1986; Nilsson et al, 2010; Ren et al, 2010) study populations, it is particularly important to consider smoking status and dose when considering the risk of disease in association with coffee consumption.

Ours is the largest prospective study of coffee intake and pancreatic cancer to date, with 1541 incident pancreatic cancer cases, and larger than the sum total from the recent Continuous Update Project (CUP) meta-analysis, which included 1460 cases identified from 13 prospective cohorts (World Cancer Research Fund and American Institute for Cancer Research, 2012). In addition to studies considered by the 2012 CUP, the totality of the evidence includes two recently reported prospective cohort 
Table 1. Hazard ratios (95\% confidence intervals) for pancreatic cancer according to coffee intake in the NIH-AARP Diet and Health Study $(\mathbf{N}=457366)$

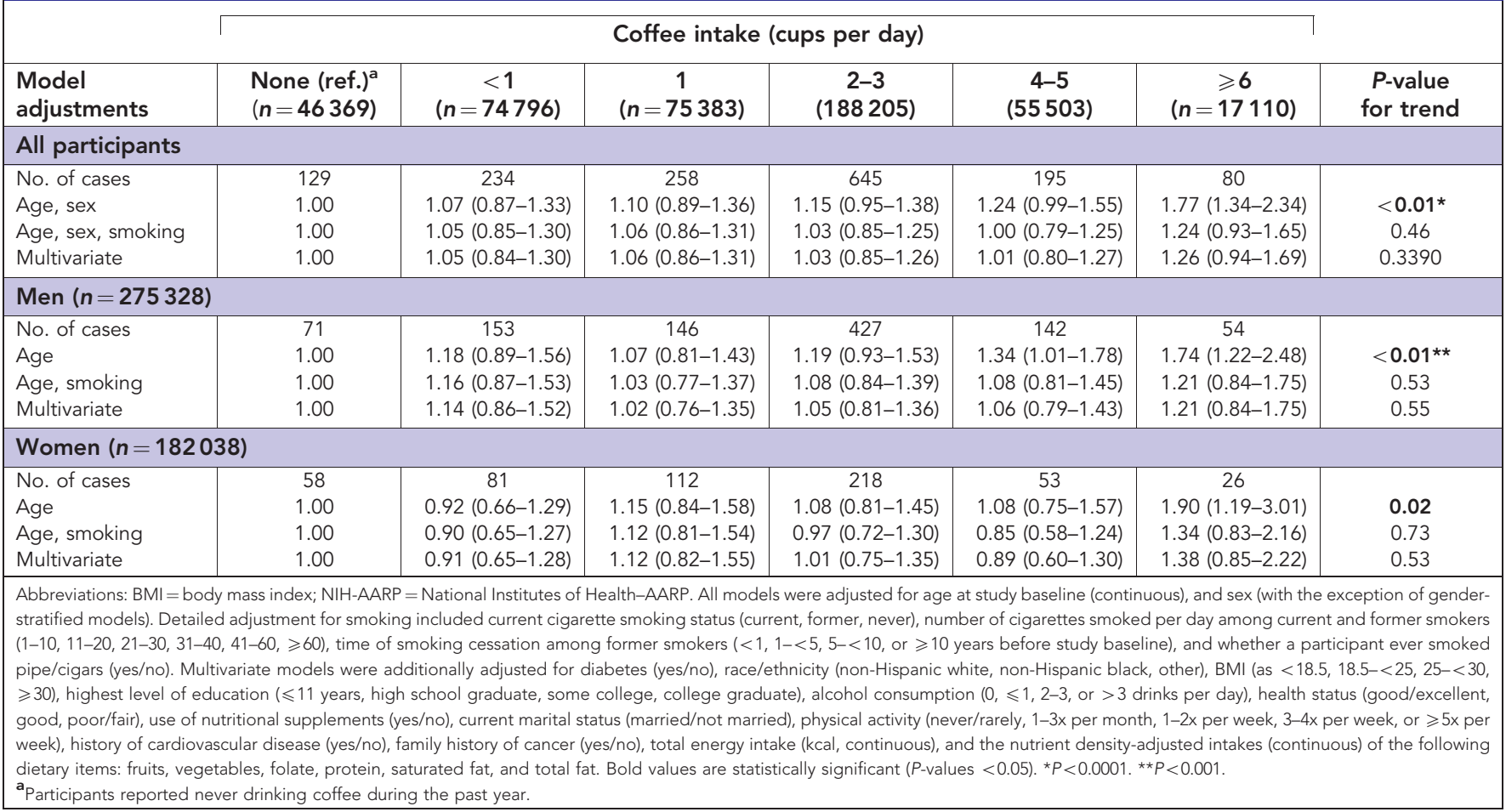

Table 2. HRs and $95 \%$ Cls for pancreatic cancer according to coffee intake in the NIH-AARP Diet and Health Study, stratified by smoking status $(n=442280)$

\begin{tabular}{|c|c|c|c|c|c|}
\hline & \multicolumn{5}{|c|}{ Coffee intake (cups per day) } \\
\hline & None (ref.) ${ }^{a}(n=46369)$ & $\leqslant 1(n=150179)$ & $2-3(n=188205)$ & $\geqslant 4(n=72613)$ & $P$-value for trend \\
\hline \multicolumn{6}{|c|}{ Current smokers $(n=65699)$} \\
\hline $\begin{array}{l}\text { No. of cases } \\
\text { HR }(95 \% \mathrm{Cl})\end{array}$ & $\begin{array}{c}15 \\
1.00\end{array}$ & $\begin{array}{c}70 \\
1.15(0.66-2.01)\end{array}$ & $\begin{array}{c}147 \\
1.10(0.65-1.88)\end{array}$ & $\begin{array}{c}106 \\
1.03(0.60-1.77)\end{array}$ & 0.57 \\
\hline \multicolumn{6}{|c|}{ Former smokers $(n=228875)$} \\
\hline $\begin{array}{l}\text { No. of cases } \\
\text { HR }(95 \% \mathrm{Cl})\end{array}$ & $\begin{array}{c}43 \\
1.00\end{array}$ & $\begin{array}{c}244 \\
1.16(0.84-1.60)\end{array}$ & $\begin{array}{c}329 \\
1.08(0.78-1.48)\end{array}$ & $\begin{array}{c}127 \\
1.18(0.83-1.67)\end{array}$ & 0.83 \\
\hline \multicolumn{6}{|c|}{ Never smokers $^{\mathbf{b}}(n=147706)$} \\
\hline $\begin{array}{l}\text { No. of cases } \\
\text { HR }(95 \% \mathrm{Cl})\end{array}$ & $\begin{array}{c}67 \\
1.00 \\
\end{array}$ & $\begin{array}{c}160 \\
0.95(0.71-1.26)\end{array}$ & $\begin{array}{c}141 \\
0.98(0.73-1.31)\end{array}$ & $\begin{array}{c}31 \\
0.97(0.63-1.48)\end{array}$ & 0.93 \\
\hline \multicolumn{6}{|c|}{$\begin{array}{l}\text { Abbreviations: } \mathrm{Cl}=\text { confidence intervals; } \mathrm{HR}=\text { hazard ratios; } \mathrm{NIH}-\mathrm{AARP}=\text { National Institutes of Health-AARP. Participants who reported that they never smoked cigarettes but smoked pipes/ } \\
\text { cigars are excluded from these analyses }(n=15086) \text {. All models were adjusted for age at study baseline (continuous), sex, number of cigarettes smoked per day among current and former } \\
\text { smokers }(1-10,11-20,21-30,31-40,41-60, \geqslant 60) \text {, time of smoking cessation among former smokers }(<1,1-<5,5-<10 \text {, or } \geqslant 10 \text { years before study baseline), and whether a participant ever } \\
\text { smoked pipe/cigars (yes } / \text { no). P-values }<0.05 \text { were considered to be statistically significant. } \\
\text { a }_{\text {Participants reported never drinking coffee during the past year. }} \\
{ }^{b} \text { Never smokers of any tobacco product (cigarettes, pipes, or cigars). }\end{array}$} \\
\hline
\end{tabular}

studies (Bhoo-Pathy et al, 2013; Bidel et al, 2013) and two pooled analyses (Turati et al, 2011; Genkinger et al, 2012).

Three previous studies from prospective cohorts have investigated associations by caffeinated and decaffeinated coffee separately (Michaud et al, 2001; Turati et al, 2012; Bhoo-Pathy et al, 2013). Our findings are consistent with those recently reported by EPIC (Bhoo-Pathy et al, 2013), with one exception; EPIC detected a small positive association between moderately low drinkers of caffeinated coffee and pancreatic cancer, compared with non-drinkers, which we did not observe in NIH-AARP. However, the authors acknowledged that the observed association among low caffeinated coffee drinkers in EPIC may be because of chance or residual confounding.
Several limitations in our study should be acknowledged. Our sample was largely Caucasian, which precluded examination of associations by race/ethnicity; our results may not be generalisable to populations with different characteristics. Coffee intake was only measured once at study baseline; however, previous studies suggest that coffee consumption is relatively stable over time (Nilsson et al, 2010; Hildebrand et al, 2012). Our results are most likely reflective of the association between filtered coffee and pancreatic cancer risk, given that this is the type of coffee predominantly consumed in the United States. Type of coffee preparation (i.e. filtered $v s$ boiled) may affect the concentration and types of constituents present in a cup of coffee and may be relevant for pancreatic cancer risk (Nilsson et al, 2010). NIH-AARP queries 
Table 3. HRs and $95 \%$ Cls for pancreatic cancer according to caffeinated and decaffeinated coffee intake in the NIH-AARP Diet and Health Study $(n=441365)$

\begin{tabular}{|c|c|c|c|c|c|}
\hline & \multicolumn{5}{|c|}{ Coffee intake (cups per day) } \\
\hline & None (ref.) ${ }^{a}$ & $\leq 1$ & $2-3$ & $\geq 4$ & $P$-value for trend \\
\hline \multicolumn{6}{|c|}{ Caffeinated coffee drinkers $(n=259908)$} \\
\hline $\begin{array}{l}\text { No. of cases } \\
\text { HR }(95 \% \mathrm{Cl})\end{array}$ & $\begin{array}{l}129 \\
1.00\end{array}$ & $\begin{array}{c}264 \\
1.13(0.92-1.40)\end{array}$ & $\begin{array}{c}449 \\
1.04(0.86-1.27)\end{array}$ & $\begin{array}{c}212 \\
1.07(0.85-1.34)\end{array}$ & 0.85 \\
\hline \multicolumn{6}{|c|}{ Decaffeinated coffee drinkers $(n=135088)$} \\
\hline $\begin{array}{l}\text { No. of cases } \\
\text { HR }(95 \% \mathrm{Cl})\end{array}$ & $\begin{array}{l}129 \\
1.00\end{array}$ & $\begin{array}{c}204 \\
0.98(0.79-1.23)\end{array}$ & $\begin{array}{c}180 \\
1.02(0.81-1.28)\end{array}$ & $\begin{array}{c}52 \\
0.96(0.69-1.33)\end{array}$ & 0.50 \\
\hline \multicolumn{6}{|c|}{$\begin{array}{l}\text { Abbreviations: } \mathrm{Cl}=\text { confidence intervals; } \mathrm{HR}=\text { hazard ratios; } \mathrm{NIH} \text {-AARP }=\text { National Institutes of Health-AARP. Participants who reported drinking coffee were classified as drinkers of caffeinated } \\
\text { coffee or decaffeinated coffee (mutually exclusive) based on which type of coffee they reported drinking more than half the time; } 16001 \text { coffee drinkers were missing caffeine data. All models } \\
\text { were adjusted for age at study baseline (continuous), sex, number of cigarettes smoked per day among current and former smokers (1-10, 11-20, 21-30, 31-40, 41-60, } \geq 60) \text {, time of smoking } \\
\text { cessation among former smokers }(<1,1-<5,5-<10, \text { or } \geq 10 \text { years before study baseline), and whether a participant ever smoked pipe/cigars (yes/no). P-values }<0.05 \text { were considered to be } \\
\text { statistically significant. } \\
\left.{ }^{2} \text { Participants reported never drinking coffee during the past year ( } n=46369\right) \text {. }\end{array}$} \\
\hline
\end{tabular}

about coffee consumption, while improved compared with many past studies, did not include these details; future studies in populations with diverse coffee consumption should examine these factors.

The prospective design is a significant strength of our study as it limits the potential that disease status influenced the self-report of coffee intake. The majority of prior evidence is limited to casecontrol studies or hospital-based cohorts, reviewed elsewhere (World Cancer Research Fund and American Institute for Cancer Research, 2007), which are vulnerable to recall bias. As compared with previous studies, we were able to more comprehensively adjust for smoking status by incorporating data on time since cessation among former smokers, which may have tempered any effects of residual confounding by smoking on our estimates. Smoking is an established risk factor for pancreatic cancer (Maisonneuve and Lowenfels, 2014) and is highly correlated with coffee drinking in the NIH-AARP Study (Guertin and Loftfield et al, 2015) and elsewhere (Nomura et al, 1986; Nilsson et al, 2010; Ren et al, 2010). Although we did not find evidence for an association, we had excellent statistical power. Our cohort included approximately two times the number of pancreatic cancer cases compared with the largest study to date (Bhoo-Pathy et al, 2013). The large size of the NIH-AARP cohort and the availability of data on coffee consumption preferences also allowed us to investigate whether effects differed between primarily caffeinated and primarily decaffeinated coffee drinkers.

This study, in addition to the previous literature, supports the 2012 conclusion of the American Institute of Cancer Research in that there is little epidemiologic evidence of an association between coffee intake and pancreatic cancer risk (World Cancer Research Fund and American Institute for Cancer Research, 2012). Our study provides evidence to extend this conclusion to both caffeinated and decaffeinated coffee drinking.

\section{ACKNOWLEDGEMENTS}

This work was supported by the Intramural Research Program of the National Institutes of Health, Division of Cancer Epidemiology and Genetics, National Cancer Institute, National Institutes of Health, and Department of Health and Human Services.

\section{CONFLICT OF INTEREST}

The authors declare no conflict of interest.

\section{REFERENCES}

Bhoo-Pathy N, Uiterwaal CS, Dik VK, Jeurnink SM, Bech BH, Overvad K, Halkjær J, Tjønneland A, Boutron-Ruault MC, Fagherazzi G, Racine A, Katzke VA, Li K, Boeing H, Floegel A, Androulidaki A, Bamia C, Trichopoulou A, Masala G, Panico S, Crosignani P, Tumino R, Vineis P, Peeters PH, Gavrilyuk O, Skeie G, Weiderpass E, Duell EJ, Arguelles M, Molina-Montes E, Navarro C, Ardanaz E, Dorronsoro M, Lindkvist B, Wallström P, Sund M, Ye W, Khaw KT, Wareham N, Key TJ, Travis RC, Duarte-Salles T, Freisling H, Licaj I, Gallo V, Michaud DS, Riboli E, Bueno-De-Mesquita HB (2013) Intake of coffee, decaffeinated coffee, or tea does not affect risk for pancreatic cancer: results from the European Prospective Investigation into Nutrition and Cancer Study. Clin Gastroenterol Hepatol 11: 1486-1492.

Bidel S, Hu G, Jousilahti P, Pukkala E, Hakulinen T, Tuomilehto J (2013) Coffee consumption and risk of gastric and pancreatic cancer-a prospective cohort study. Int J Cancer 132: 1651-1659.

Bosetti C, Lucenteforte E, Silverman DT, Petersen G, Bracci PM, Ji BT, Negri E, Li D, Risch HA, Olson SH, Gallinger S, Miller AB, Bueno-de-Mesquita HB, Talamini R, Polesel J, Ghadirian P, Baghurst PA, Zatonski W, Fontham E, Bamlet WR, Holly EA, Bertuccio P, Gao YT, Hassan M, Yu H, Kurtz RC, Cotterchio M, Su J, Maisonneuve P, Duell EJ, Boffetta P, La Vecchia C (2012) Cigarette smoking and pancreatic cancer: an analysis from the International Pancreatic Cancer Case-Control Consortium (Panc4). Ann Oncol 23: $1880-1888$

Cornelis MC (2015) Toward systems epidemiology of coffee and health. Curr Opin Lipidol 26: 20-29.

Dong J, Zou J, Yu XF (2011) Coffee drinking and pancreatic cancer risk: a meta-analysis of cohort studies. World J Gastroenterol 17: 1204-1210.

Genkinger JM, Li R, Spiegelman D, Anderson KE, Albanes D, Bergkvist L, Bernstein L, Black A, van den Brandt PA, English DR, Freudenheim JL, Fuchs CS, Giles GG, Giovannucci E, Goldbohm RA, Horn-Ross PL, Jacobs EJ, Koushik A, Männistö S, Marshall JR, Miller AB, Patel AV, Robien K, Rohan TE, Schairer C, Stolzenberg-Solomon R, Wolk A, Ziegler RG, Smith-Warner SA (2012) Coffee, tea, and sugar-sweetened carbonated soft drink intake and pancreatic cancer risk: a pooled analysis of 14 cohort studies. Cancer EpidemiolBiomarkers Prev 21: 305-318.

Guertin KA, Freedman ND, Loftfield E, Graubard BI, Caporaso NE, Sinha R (2015) Coffee consumption and incidence of lung cancer in the NIHAARP Diet and Health Study. Int J Epidemiol; e-pub head of print 16 January 2015; doi:10.1093/ije/dyv104.

Guertin KA, Loftfield E, Boca SM, Sampson JN, Moore SC, Xiao Q, Huang WY, Xiong X, Freedman ND, Cross AJ, Sinha R (2015) Serum biomarkers of habitual coffee consumption may provide insight into the mechanism underlying the association between coffee consumption and colorectal cancer. Am J Clin Nutr 101(5): 1000-1011.

Hildebrand JS, Patel AV, McCullough ML, Gaudet MM, Chen AY, Hayes RB, Gapstur SM (2012) Coffee, tea, and fatal oral/pharyngeal cancer in a large prospective US cohort. Am J Epidemiol 177(1): 50-58.

Howlader N, Noone AM, Krapcho M, Garshell J, Miller D, Altekruse SF, Kosary CL, Yu M, Ruhl J, Tatalovich Z, Mariotto A, Lewis DR, Chen HS, 
Feuer EJ, Cronin KA (eds) (2015) SEER Cancer Statistics Review, 19752012. National Cancer Institute: Bethesda, MD, USA, Available at http://seer.cancer.gov/csr/1975_2012/(based on November 2014 SEER data submission, posted to the SEER website, April 2015).

Klein AP, Lindström S, Mendelsohn JB, Steplowski E, Arslan AA, Bueno-deMesquita HB, Fuchs CS, Gallinger S, Gross M, Helzlsouer K, Holly EA, Jacobs EJ, Lacroix A, Li D, Mandelson MT, Olson SH, Petersen GM, Risch HA, Stolzenberg-Solomon RZ, Zheng W, Amundadottir L, Albanes D, Allen NE, Bamlet WR, Boutron-Ruault MC, Buring JE, Bracci PM, Canzian F, Clipp S, Cotterchio M, Duell EJ, Elena J, Gaziano JM, Giovannucci EL, Goggins M, Hallmans G, Hassan M, Hutchinson A, Hunter DJ, Kooperberg C, Kurtz RC, Liu S, Overvad K, Palli D, Patel AV, Rabe KG, Shu XO, Slimani N, Tobias GS, Trichopoulos D, Van Den Eeden SK, Vineis P, Virtamo J, Wactawski-Wende J, Wolpin BM, Yu H, Yu K, Zeleniuch-Jacquotte A, Chanock SJ, Hoover RN, Hartge P, Kraft P (2013) An absolute risk model to identify individuals at elevated risk for pancreatic cancer in the general population. PLoS One 8 : e72311.

Maisonneuve P, Lowenfels AB (2014) Risk factors for pancreatic cancer: a summary review of meta-analytical studies. Int J Epidemiol 44(1): 186-198.

Michaud DS, Giovannucci E, Willett WC, Colditz GA, Fuchs CS (2001) Coffee and alcohol consumption and the risk of pancreatic cancer in two prospective United States cohorts. Cancer Epidemiol Biomarkers Prev 10: 429-437.

Michaud DS, Midthune D, Hermansen S, Leitzmann M, Harlan LC, Kipnis V, Schatzkin A (2005) Comparison of cancer registry case ascertainment with SEER estimates and self-reporting in a subset of the NIH-AARP Diet and Health Study. J Registry Manage 32: 70-77.

Nilsson L, Johansson I, Lenner P, Lindahl B, Van Guelpen B (2010) Consumption of filtered and boiled coffee and the risk of incident cancer: a prospective cohort study. Cancer Causes Control 21: 1533-1544.
Nishi M, Ohba S, Hirata K, Miyake H (1996) Dose-response relationship between coffee and the risk of pancreas cancer. Jpn J Clin Oncol 26: 42-48.

Nomura A, Heilbrun LK, Stemmermann GN (1986) Prospective study of coffee consumption and the risk of cancer. J Natl Cancer Inst 76: 587-590.

Ren JS, Freedman ND, Kamangar F, Dawsey SM, Hollenbeck AR, Schatzkin A, Abnet CC (2010) Tea, coffee, carbonated soft drinks and upper gastrointestinal tract cancer risk in a large United States prospective cohort study. Eur J Cancer 46: 1873-1881.

Schatzkin A, Subar AF, Thompson FE, Harlan LC, Tangrea J, Hollenbeck AR, Hurwitz PE, Coyle L, Schussler N, Michaud DS, Freedman LS, Brown CC, Midthune D, Kipnis V (2001) Design and serendipity in establishing a large cohort with wide dietary intake distributions: the National Institutes of Health-American Association of Retired Persons Diet and Health Study. Am J Epidemiol 154: 1119-1125.

Turati F, Galeone C, Edefonti V, Ferraroni M, Lagiou P, La Vecchia C, Tavani A (2012) A meta-analysis of coffee consumption and pancreatic cancer. Ann Oncol 23: 311-318.

Turati F, Galeone C, Talamini R, Franceschi S, Manzari M, Gallino G, Polesel J, La Vecchia C, Tavani A (2011) Coffee, decaffeinated coffee, tea, and pancreatic cancer risk: a pooled-analysis of two Italian case-control studies. Eur J Cancer Prev 20: 287-292.

World Cancer Research Fund and American Institute for Cancer Research (2007) Food, Nutrition, Physical Activity, and the Prevention of Cancer: A Global Perspective. AICR: Washington, DC, USA.

World Cancer Research Fund and American Institute for Cancer Research (2012) Continuous Update Project Summary. Food, Nutrition, Physical Activity, and the Prevention of Pancreatic Cancer [Online]. Available at http://www.dietandcancerreport.org (last accessed 15 May 2015).

World Health Organization (2010) International Classification of Diseases for Oncology. ICD-O-3, 3rd ed. WHO: Geneva, Switzerland.

Supplementary Information accompanies this paper on British Journal of Cancer website (http://www.nature.com/bjc) 